\title{
Decreased Signs of Nicotine Withdrawal in Mice Null for the $\beta 4$ Nicotinic Acetylcholine Receptor Subunit
}

\author{
Ramiro Salas, Fredalina Pieri, and Mariella De Biasi \\ Division of Neuroscience, Baylor College of Medicine, Houston, Texas 77030
}

Withdrawal from chronic exposure to nicotine, the main addictive component of tobacco, produces distinctive symptoms in humans. The appearance of these symptoms is a major deterrent when people try to quit smoking. To study which type of nicotine receptor is relevant for the onset of the withdrawal syndrome, we used a mouse model of nicotine withdrawal. Wild-type mice and mice null for the $\beta 4$ $(\beta 4-/-)$ or the $\beta 2(\beta 2-/-)$ nicotinic acetylcholine receptor subunits were implanted with osmotic minipumps delivering $24 \mathrm{mg} \cdot \mathrm{kg}^{-1} \cdot \mathrm{d}^{-1}$ nicotine for $13 \mathrm{~d}$. Subsequently, a single intraperitoneal injection of the nicotinic receptor antagonist mecamylamine induced behavioral symptoms of withdrawal measured as increased grooming, chewing, scratching, and shaking, plus the appearance of some unique behaviors such as jumping, leg tremors, and cage scratching. Mecamylamine injection triggered comparable withdrawal signs in wild-type and in $\beta 2-1-$ mice, whereas the $\beta 4-1-$ mice displayed significantly milder somatic symptoms. In addition, nicotine withdrawal produced hyperalgesia in wild-type but not $\beta 4-1-$ mice. Finally, chronic nicotine produced an increase in epibatidine binding in several areas of the brain in both wild-type and in $\beta 4-1-$ mice, but such receptor upregulation did not correlate with the severity of withdrawal signs.

Our results demonstrate a major role for $\beta 4$-containing nicotinic acetylcholine receptors in the appearance of nicotine withdrawal symptoms. In contrast, the $\beta 2$ subunit does not seem to greatly influence this phenomenon. We also show that the upregulation of epibatidine binding sites attributable to chronic nicotine, an effect associated with $\beta 2$-containing receptors, is probably not related to the mechanisms underlying withdrawal.

Key words: nicotinic acetylcholine receptor; knock-out mice; $\beta 4$ subunit; $\beta 2$ subunit; nicotine; withdrawal

\section{Introduction}

Nicotine, the major addictive component of tobacco, binds to nicotinic acetylcholine receptors (nAChRs). These receptors are usually heteropentamers composed of at least one type of $\alpha$ and one type of $\beta$ subunit. The $\alpha 7-\alpha 10$ subunits are the exception, because they are believed to form $\alpha$-only homopentamers and heteropentamers. To date, nine $\alpha$ and three $\beta$ subunits have been cloned. Some $\alpha / \beta$ subunit combinations, such as $\alpha 4 \beta 2, \alpha 3 \beta 4$, $\alpha 6 \beta 2 \beta 3$, or $\alpha 7$ only, seem to be favored in neurons. Among these, the most widely expressed are the $\alpha 4 \beta 2$ - and $\alpha 7$-containing combinations. $\alpha 4 \beta 2 \mathrm{nAChRs}$ are also responsible for most of the high-affinity nicotine binding sites and have been the focus of many studies in the field (Dani and De Biasi, 2001; Hogg et al., 2003).

Determining the roles of each nAChR subtype in physiology and addiction is one of the major goals in nicotine research, and the study of mice carrying null mutations for several nAChR subunits has indicated the involvement of certain subunits in specific nicotinic mechanisms. Examples are as follows: the in-

Received May 18, 2004; revised Sept. 20, 2004; accepted Sept. 20, 2004

This work was supported by National Institute on Drug Abuse Grant DA017173 (M.D.). We thank Dr. David Gangitano for the useful comments and Tetyana Aleksenko for excellent technical support.

Correspondence should be addressed to Mariella De Biasi, Division of Neuroscience, Baylor College of Medicine, Houston, TX 77030. E-mail debiasi@bcm.tmc.edu.

DOI:10.1523/JNEUROSCI.1939-04.2004

Copyright $\odot 2004$ Society for Neuroscience $\quad$ 0270-6474/04/2410035-05\$15.00/0 volvement of $\alpha 4$ in nicotine-dependent antinociception (Marubio et al., 1999), $\alpha 4, \beta 3$, and $\beta 4$ in anxiety-related behaviors (Booker et al., 2000; Ross et al., 2000; Salas et al., 2003a), $\beta 2$ in fear conditioning and cocaine-induced nicotine selfadministration (Picciotto et al., 1998), $\alpha 7$ in neuronal protection (Laudenbach et al., 2002), and $\alpha 3, \alpha 5$, and $\beta 4$ in nicotineinduced seizures (Salas et al., 2003b, 2004; Kedmi et al., 2004).

The appearance of withdrawal symptoms after chronic nicotine cessation is an important clinical effect of nicotine, because it is one of the major factors precluding people from successfully quitting smoking. The mechanisms underlying the physical and affective symptoms of withdrawal are poorly understood, and which nAChRs subtypes are involved in this aspect of nicotine addiction is still uncertain. Nicotine withdrawal can be precipitated in mice by antagonists with preferential effects on $\alpha 3 \beta 4$-, $\alpha 4 \beta 2$-, or $\alpha 7$-containing nAChRs (Damaj et al., 2003). The present study addressed the role of $\beta 2$ - and $\beta 4$-containing $\mathrm{nAChRs}$ in mediating the somatic signs of nicotine withdrawal by using mice null for either the $\beta 2$ or the $\beta 4 \mathrm{nAChR}$ subunits.

\section{Materials and Methods}

Animals. We studied 2- to 5-month-old wild-type mice and mice lacking the $\beta 2$ or the $\beta 4$ subunit of $\mathrm{nAChRs} \mathrm{(Xu} \mathrm{et} \mathrm{al.,} \mathrm{1999).} \mathrm{All} \mathrm{mice} \mathrm{were}$ backcrossed for 8-10 generations into a C57BL/6J background. Male and female mice were housed under a $12 \mathrm{hr}$ light/dark cycle, with access to food and water ad libitum, and experiments were performed during the light phase. Alzet pumps model 1004 (14 d, flow rate of $0.25 \mu \mathrm{l} / \mathrm{hr}$; 
Durect, Cupertino, CA) were subcutaneously implanted according to the instructions of the manufacturer. Pumps were filled with either saline or $(-)$ nicotine tartrate in saline to deliver a $24 \mathrm{mg} \cdot \mathrm{kg}^{-1} \cdot \mathrm{d}^{-1}$ dose of nicotine (as free base) for $13 \mathrm{~d}$. The experimenters were blind to the genotypes until data were gathered and analyzed. All procedures were approved by the Baylor College of Medicine Animal Care and Use Committee and followed the guidelines for animal intramural research from the National Institutes of Health.

Nicotine withdrawal. Our mouse nicotine withdrawal protocol was based on the research by Berrendero et al. (2002) and Damaj et al. (2003). After $13 \mathrm{~d}$ of either nicotine or saline infusion, mice were scored for somatic signs for a $5 \mathrm{~min}$ period to obtain a baseline of behavioral scores during chronic exposure to nicotine. Subsequently, the mice were intraperitoneally injected with $3 \mathrm{mg} / \mathrm{kg}$ racemic mecamylamine and immediately placed in the home cage, where withdrawal signs were recorded for $20 \mathrm{~min}$. The following parameters were monitored: grooming, scratching, chewing, shaking, cage scratching, head nodding, and jumping. A pilot study conducted on drug-naive C57BL/6J mice indicated that 3 $\mathrm{mg} / \mathrm{kg}$ mecamylamine does not increase withdrawal signs under our experimental conditions. Data were analyzed by ANOVA, followed by Newman-Keuls post hoc comparisons. Nicotine tartrate and mecamylamine were purchased from Sigma (St. Louis, MO).

Hyperalgesia. We measured nicotine-induced hyperalgesia on mice undergoing either spontaneous or mecamylamine-induced nicotine withdrawal and found that hyperalgesia was more reliably observed in the mice undergoing withdrawal after depletion of the nicotine infusion pumps. Therefore, tail-flick and hot-plate experiments were performed $2 \mathrm{~d}$ after interruption of the nicotine infusion. First, the tail of a mouse was manually inserted into a $48^{\circ} \mathrm{C}$ water bath, and the time to remove the tail was recorded (tail flick). Immediately after tail flick, mice were placed on a platform at $51^{\circ} \mathrm{C}$, and the latency time to lick their paws or to jump was recorded (hot plate).

Epibatidine binding. After nicotine withdrawal symptoms were recorded, mice were killed, and brains removed and rapidly frozen in $-20^{\circ} \mathrm{C}$ isopentane. Binding was performed as described previously (Franceschini et al., 2002). Briefly, fresh frozen $20 \mu \mathrm{m}$ sections were cut, incubated in binding buffer (in mM: 50 Tris base, pH 7.4, $120 \mathrm{NaCl}, 5$ $\mathrm{KCl}, 2.5 \mathrm{CaCl}_{2}$, and $1 \mathrm{MgCl}_{2}$ ) for $10 \mathrm{~min}$ and then in $500 \mathrm{pm}\left[{ }^{125} \mathrm{I}\right] \mathrm{epi}$ batidine (specific activity, $2200 \mathrm{Ci} / \mathrm{mmol}$; NEN, Boston, MA) in binding buffer for $2 \mathrm{hr}$. Some sections were treated with $500 \mathrm{pm}\left[{ }^{125} \mathrm{I}\right]$ epibatidine plus $100 \mathrm{~nm}$ cold cytisine (Sigma) as competitor. Sections were subsequently washed in binding buffer, rinsed in water, dried, and exposed to Biomax film (Eastman Kodak, Rochester, NY) for 1 and 16 hr. Quantification of binding was performed as described previously (Broide et al., 2002). Statistical significance of the difference in signal density of the nicotine versus saline treatment groups was determined by Student's $t$ test, as well as two-way ANOVA.

\section{Results \\ $\beta 4-/-$ but not $\beta 2-/-$ mice show decreased nicotine withdrawal signs}

During the 20 min of observation after mecamylamine injection, control mice chronically treated with nicotine exhibited significantly more somatic signs of withdrawal than saline-treated mice (Fig. 1A). After mecamylamine injection, nicotine-treated $\beta 2-/-$ mice displayed withdrawal scores similar to those of nicotine-treated control mice. Saline-treated $\beta 2-/-$ mice showed no difference compared with saline-treated controls (Fig. $1 A)$. In contrast, after mecamylamine injection, nicotine-treated $\beta 4-/-$ mice showed a decreased amount of symptoms when compared with nicotine-treated control or $\beta 2-/-$ mice (Fig. $1 A)$. The behavior of saline-treated $\beta 4-/-$ mice was indistinguishable from that of saline-treated wild-type and nicotinetreated $\beta 4-/-$ mice $(25 \pm 6,22 \pm 3$, and $21 \pm 3$ signs, respectively). When each of the four major withdrawal symptoms (shaking, grooming, scratching, and chewing) were studied separately, $\beta 4-/-$ mice scored at lower levels in every case (Fig.

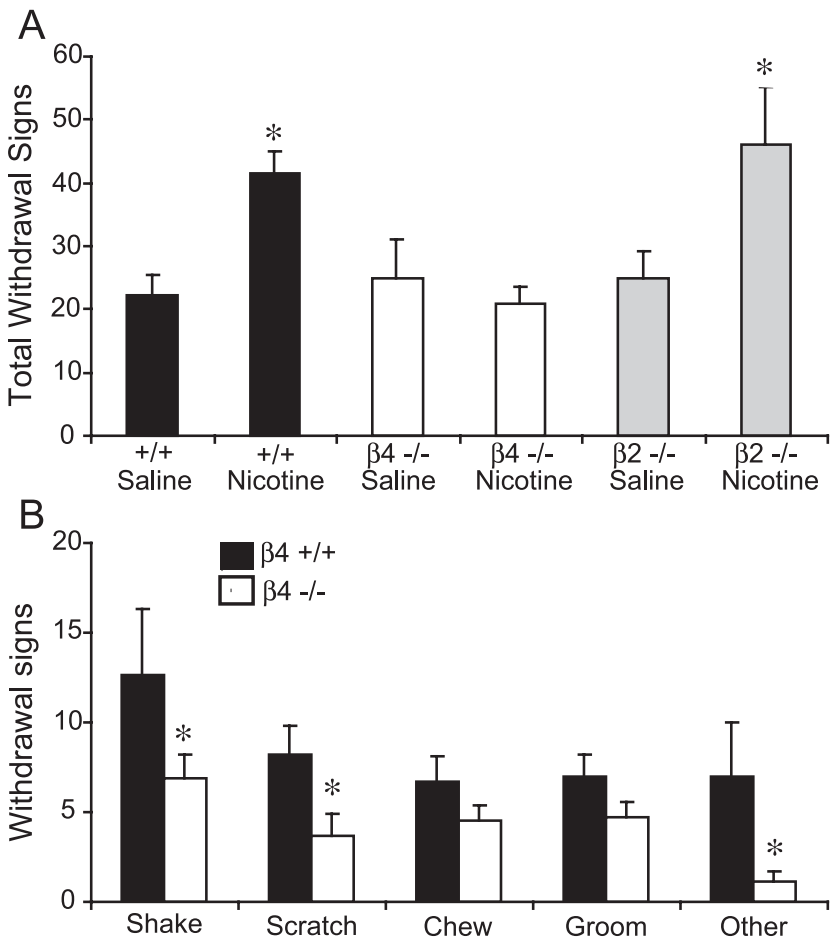

Figure 1. Mecamylamine-induced withdrawal signs in wild-type, $\beta 4-/-$, and $\beta 2-/-$ mice. $A$, Total nicotine withdrawal signs in control mice $(+/+$, black bars) treated with saline ( $n=6)$ or nicotine $(n=21), \beta 4-/-$ mice (white bars) treated with saline $(n=4)$ or nicotine $(n=18)$, and $\beta 2-/-$ mice (gray bars) treated with saline $(n=7)$ or nicotine $(n=$ 7) during the 20 min immediately after mecamylamine injection. $B$, Comparison of different withdrawal signs between wild-type (black bars) and $\beta 4-/-$ mice (white bars). The 0ther bar refers to other symptoms such as leg shakes, head nods, rear leg digging, and cage scratching. ${ }^{*} p<0.05$ versus saline for the same genotype (ANOVA and Newman-Keuls post hoc comparisons) $(A)$ versus $+/+(B)$.

$1 B)$. Some behaviors such as "hindpaw digging," jumping, and cage scratching were seen in very few mice. These behaviors were unique to wild-type and $\beta 2-/-$ mice after mecamylamine, were never observed before mecamylamine injection, and did not appear in $\beta 4-/-$ mice.

To verify whether nonsomatic signs of withdrawal are also altered in $\beta 4-/-$ mice, we conducted hot-plate and tail-flick experiments. As expected (Damaj et al., 2003), nicotine withdrawal elicited hyperalgesia in the hot-plate test. The latency to lick or jump was $11.9 \pm 1.2 \mathrm{sec}$ for saline-treated $\beta 4+/+$ mice and $8.0 \pm 1.0 \mathrm{sec}$ for nicotine-treated $\beta 4+/+\operatorname{mice}(n=7$ and 8 , respectively; $p<0.05)$. In contrast, in $\beta 4-/-$ mice, nicotine did not produce hyperalgesia. The latency to lick or jump was $9.4 \pm$ $1.6 \mathrm{sec}$ in saline-treated $\beta 4-/-$ mice and $15.6 \pm 2.1 \mathrm{sec}$ in nicotine-treated $\beta 4-/-$ mice ( $n=8$ and 5 , respectively). These results demonstrate that both somatic and nonsomatic signs of nicotine withdrawal are affected in the $\beta 4-/-$ mice. In the tailflick test, the same trend was observed, but the data did not reach statistical significance in any of the experimental conditions tested.

\section{Upregulation of epibatidine binding does not correlate with the onset of withdrawal signs}

Immediately after withdrawal symptoms were scored for each mouse, brains were harvested, rapidly dissected, and frozen to perform $\left[{ }^{125} \mathrm{I}\right]$ epibatidine binding on brain sections. As expected, epibatidine binding was increased during nicotine treat- 


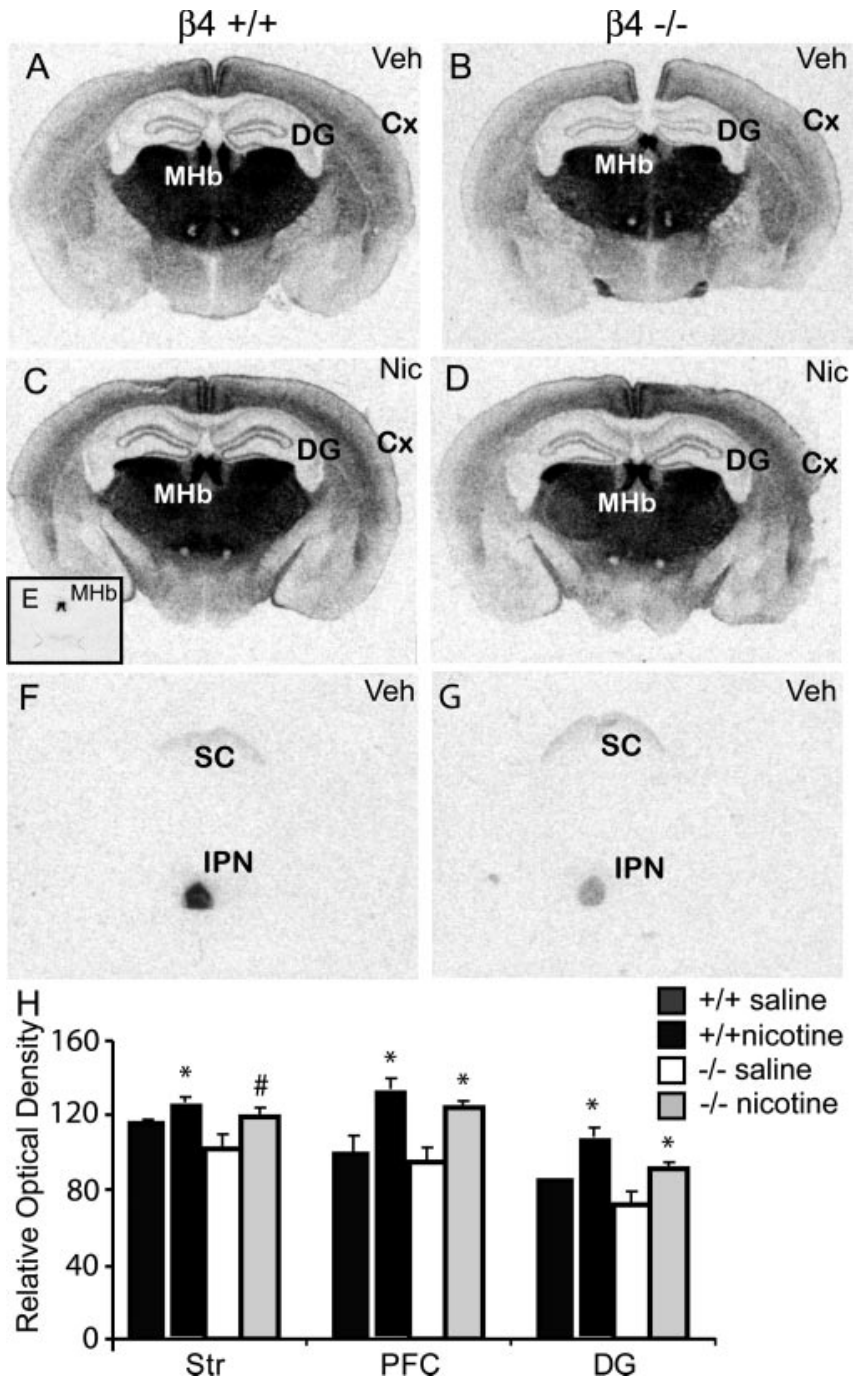

Figure 2. Epibatidine binding in wild-type and $\beta 4-/-$ mouse brain sections. $A-E, M H b$ level. $F$, G, IPN level. $A$, Saline-treated (Veh) $\beta 4+/+$ mouse. $B$, Saline-treated (Veh) $\beta 4-1-$ mouse. C, Nicotine-treated (Nic) $\beta 4+/+$ mouse. D, Nicotine-treated (Nic) $\beta 4-/-$ mouse. $E, \beta 2-/-$ mouse. $F$, Saline-treated (Veh) $\beta 4+/+$ mouse; epibatidine binding has been competed with cytisine. G, Saline-treated (Veh) $\beta 4-1$ - mouse; epibatidine binding has been competed with cytisine. $H$, Quantification of epibatidine binding in striatum (Str), prefrontal cortex (PFC), and dentate gyrus (DG). $n=3-6$ per group. ${ }^{*} p<0.05 ;{ }^{\#} p<0.1$; Student's t test versus corresponding saline. A two-factor ANOVA analysis of the data indicated that there was a significant effect of genotype (Str, PFC, and DG, $p<0.05$ ) and treatment (Str and PFC, $p<$ $0.01 ; \mathrm{DG}, p<0.05$ ) but no treatment $\times$ genotype interaction ( $p>0.6$ in all cases), confirming that $\beta 4-1-$ mice upregulate epibatidine binding sites during chronic nicotine treatment. Cx, Cortex; SC, superior colliculus.

ment in control mice (Marks et al., 1983; Schwartz and Kellar, 1983). This increase occurred in brain regions such as cortex, striatum, and hippocampus (Fig. $2 A, C, H$ ). In $\beta 4-/-$ mice, epibatidine binding was also increased by chronic nicotine treatment, and binding levels were indistinguishable from those of control mice in areas dominated by $\alpha 4 \beta 2$ type receptors, including cortex, striatum, and thalamus (Fig. $2 B, D, H$ ). The medial habenula $(\mathrm{MHb})$ and the interpenduncular nucleus (IPN) of $\beta 4-/-$ mice showed lower epibatidine binding than in control mice, because these regions express mainly $\alpha 3 \beta 4$ type receptors (Nguyen et al., 2003). To discern between $\alpha 4 \beta 2$-containing and non- $\alpha 4 \beta 2$-containing nAChRs, we competed the binding of epibatidine with an excess of cold cytisine. Under these conditions, epibatidine binds mainly to $\alpha 6 / \beta 3$ - and $\alpha 3 / \beta 4$-containing recep- tors. As expected, $\beta 4-/-$ mouse brains contained much lower epibatidine binding activity after cytisine competition in the $\mathrm{MHb}$ and IPN (Fig. 2F,G). However, those lower levels of cytisine-competed epibatidine binding were unaffected by nicotine treatment (data not shown). Finally, as previously documented (Picciotto et al., 1995), epibatidine binding was significantly decreased in most areas of $\beta 2-/-$ mouse brains. As shown in Figure $2 E$, epibatidine binding was only visible on the $\mathrm{MHb}$, medial habenula, superior colliculus, and other regions rich in $\beta 4$-containing receptors.

\section{Discussion}

We have shown that the lack of $\beta 4$-containing $\mathrm{nAChRs}$ is enough to substantially decrease the somatic signs of mecamylamineinduced nicotine withdrawal. In addition, the $\beta 4$ null mutation reduces hyperalgesia, a nonsomatic sign observed during nicotine withdrawal. Interestingly, $\beta 2$-containing $\mathrm{nAChRs,} \mathrm{which}$ have been implicated in nicotine self-administration (Picciotto et al., 1998), do not seem to influence the onset of nicotine withdrawal symptoms.

Like other drugs of addiction, initial nicotine use produces positive affective states, but its prolonged use triggers neuroadaptations that contribute to both the phenomenon of dependence and the negative reinforcement aspects of nicotine use (Laviolette and van der Kooy, 2004). Our results imply that the $\mathrm{nAChR}$ subtypes that mediate the positive-reinforcing effects of nicotine might be different from those mediating its negativereinforcing effects. This is of considerable interest because withdrawal symptoms are among the major causes of failure when smokers try to quit (West et al., 1989), and therapeutic measures toward the minimization of withdrawal symptoms might aid in smoking cessation.

In mice, nicotine withdrawal produces somatic signs such as head shakes and paw tremors, as well as nonsomatic signs such as hyperalgesia and anxiety-like responses in the elevated plus maze (Damaj et al., 2003). Mecamylamine, which has a slightly higher selectivity for $\alpha 3 \beta 4$-containing nAChRs than for other $\alpha / \beta$ combinations (Papke et al., 2001), is the most effective antagonist at precipitating both somatic and nonsomatic withdrawal signs. Dihydro- $\beta$-erythroidine, a relatively selective antagonist for $\alpha 4 \beta 2$-containing $\mathrm{nAChRs,} \mathrm{can} \mathrm{precipitate} \mathrm{anxiety-like} \mathrm{re-}$ sponses, and methyllycaconitine, an $\alpha 7$-containing nAChR antagonist, selectively precipitates hyperalgesia (Damaj et al., 2003). In rats also, mecamylamine precipitates both somatic and nonsomatic withdrawal signs (Malin et al., 1994). These data, together with our findings, confirm the dominant role of $\beta 4$ containing $\mathrm{nAChRs}$ in mediating the negative-reinforcing properties of nicotine.

A major open question is where does mecamylamine act and which neural circuits underlie nicotine withdrawal. In humans, nicotine withdrawal is characterized by bradycardia, gastrointestinal discomfort, insomnia, increased appetite, (Hughes et al., 1991), depressed mood, irritability, anxiety, frustration, difficulty concentrating, and craving for tobacco (Lewis, 1996), suggesting that both peripheral and central mechanisms contribute to the withdrawal syndrome. Studies conducted in rodents also indicate that the signs of nicotine withdrawal have a central and a peripheral component (Watkins et al., 2000). The mesolimbic dopamine nuclei implicated in the positive-reinforcing effects of nicotine are among the candidate areas mediating some of the centrally mediated aversive effects of withdrawal, because injection of mecamylamine in the ventral tegmental area (VTA) has been shown to elicit withdrawal signs such as gasps, teeth chatter, 
and hypolocomotion in rats (Hildebrand et al., 1999). However, $\beta 4$-containing $\mathrm{nAChRs}$ are expressed at relatively low densities in the VTA (Klink et al., 2001; Salas et al., 2003a), suggesting that $\beta 4$-containing $\mathrm{nAChRs}$ in other brain areas might be important for nicotine withdrawal. Indeed, besides the olfactory bulb and pineal gland, the $\beta 4$ subunit is expressed in the CNS at high levels only in the MHb and the IPN (Quick et al., 1999; Klink et al., 2001; Salas et al., 2003a), which are part of the dorsal diencephalic system (Sutherland, 1982). Rich projections from and to the diencephalic system might explain the effect of $\beta 4$-containing $\mathrm{nAChRs}$ on the mesolimbic system. For example, the MHb sends projections to the IPN but also to the VTA, while receiving projections from the nucleus accumbens. In addition, the IPN sends projections to the raphe nuclei, which in turn projects to the VTA (Maisonneuve and Glick, 2003).

The peripheral symptoms of nicotine deprivation are likely to be mediated by the autonomic nervous system, and the $\beta 4$ subunit is highly expressed in both sympathetic and parasympathetic ganglia (Xu et al., 1999; De Biasi, 2002). The aspects of autonomic function studied so far in the $\beta 4-/-$ mice indicate that the absence of $\beta 4$ alone does not alter organ function in basal, nonchallenged conditions (Xu et al., 1999; Salas et al., 2003a; Wang et al., 2003). However, $\beta 4$-mediated mechanisms might become relevant during chronic nicotine exposure and/or mecamylamineinduced withdrawal.

Other nAChR subunits are probably implicated in nicotine withdrawal symptoms. $\alpha 3$ heterozygous and $\alpha 5$ null mice have a phenotype similar to that of $\beta 4-/-$ mutants in that they are less sensitive to acute nicotine than controls (Salas et al., 2003b, 2004; Kedmi et al., 2004). In addition, the $\alpha 3$ and $\alpha 5$ subunits are coexpressed with $\beta 4$ in the MHb, the IPN, and peripheral ganglia. Therefore, it is likely that these two subunits are also involved in the mechanisms of nicotine withdrawal. The role of the $\alpha 6, \alpha 7$, and $\beta 3$ subunits in nicotine withdrawal is yet to be determined. These subunits are expressed in the VTA (Franceschini et al., 2002; Salas et al., 2003a; Wooltorton et al., 2003), which puts them in an ideal position to affect the rewarding effects of nicotine.

One of the most extensively studied effects of long-term nicotine in humans and rodents is the upregulation of receptor expression and function during nicotine treatment (Marks et al., 1983; Schwartz and Kellar, 1983; Nguyen et al., 2003). This effect, which occurs mainly for $\beta 2$-containing $\mathrm{nAChRs}$, has been hypothesized to be critical for the development of nicotine addiction. Epibatidine binds to several $\mathrm{nAChR}$ populations in the brain, including $\alpha 4 \beta 2$ - and $\alpha 3 \beta 4$-containing receptors. We have shown that epibatidine binding is upregulated in $\beta 4-/-$ mice, but these mice show a decrease in the somatic as well as nonsomatic signs of withdrawal. Conversely, $\beta 2-/-$ mice, which lack $\alpha 4 \beta 2$ nAChRs, do undergo withdrawal. In addition, the $\beta 4$ component of epibatidine binding in the brain is not upregulated by nicotine (Nguyen et al., 2003), suggesting that nAChR upregulation is not critical for the appearance of nicotine withdrawal symptoms.

In conclusion, we have shown that the $\beta 4$ subunit of nAChRs is critical for nicotine withdrawal symptoms in mice, whereas the $\beta 2$ subunit is not. These data can be of importance in the effort to develop new and more effective drugs to help smoking cessation.

\section{References}

Berrendero F, Kieffer BL, Maldonado R (2002) Attenuation of nicotineinduced antinociception, rewarding effects, and dependence in $\mu$-opioid receptor knock-out mice. J Neurosci 22:10935-10940.
Booker TK, Tritto T, Colman J, Cui C, Collins AC, Heinemann SF (2000) Beta3 subunits in regulation of anxiety: analysis of beta3 null mutant mice. In: The 20th Neuropharmacology Conference, p 65. New Orleans: Elsevier Science.

Broide RS, Salas R, Ji D, Paylor R, Patrick JW, Dani JA, De Biasi M (2002) Increased sensitivity to nicotine-induced seizures in mice expressing the L250T alpha 7 nicotinic acetylcholine receptor mutation. Mol Pharmacol 61:695-705.

Damaj MI, Kao W, Martin BR (2003) Characterization of spontaneous and precipitated nicotine withdrawal in the mouse. J Pharmacol Exp Ther 307:526-534.

Dani JA, De Biasi M (2001) Cellular mechanisms of nicotine addiction. Pharmacol Biochem Behav 70:439-446.

De Biasi M (2002) Nicotinic mechanisms in the autonomic control of organ systems. J Neurobiol 53:568-579.

Franceschini D, Paylor R, Broide R, Salas R, Bassetto L, Gotti C, De Biasi M (2002) Absence of alpha7-containing neuronal nicotinic acetylcholine receptors does not prevent nicotine-induced seizures. Brain Res Mol Brain Res 98:29-40.

Hildebrand BE, Panagis G, Svensson TH, Nomikos GG (1999) Behavioral and biochemical manifestations of mecamylamine-precipitated nicotine withdrawal in the rat: role of nicotinic receptors in the ventral tegmental area. Neuropsychopharmacology 21:560-574.

Hogg RC, Raggenbass M, Bertrand D (2003) Nicotinic acetylcholine receptors: from structure to brain function. Rev Physiol Biochem Pharmacol 147:1-46.

Hughes JR, Gust SW, Skoog K, Keenan RM, Fenwick JW (1991) Symptoms of tobacco withdrawal. A replication and extension. Arch Gen Psychiatry 48:52-59.

Kedmi M, Beaudet AL, Orr-Urtreger A (2004) Mice lacking neuronal nicotinic acetylcholine receptor beta4-subunit and mice lacking both alpha5and beta4-subunits are highly resistant to nicotine-induced seizures. Physiol Genomics 17:221-229.

Klink R, de Kerchove d'Exaerde A, Zoli M, Changeux JP (2001) Molecular and physiological diversity of nicotinic acetylcholine receptors in the midbrain dopaminergic nuclei. J Neurosci 21:1452-1463.

Laudenbach V, Medja F, Zoli M, Rossi FM, Evrard P, Changeux JP, Gressens P (2002) Selective activation of central subtypes of the nicotinic acetylcholine receptor has opposite effects on neonatal excitotoxic brain injuries. FASEB J 16:423-425.

Laviolette SR, van der Kooy D (2004) The neurobiology of nicotine addiction: bridging the gap from molecules to behaviour. Nat Rev Neurosci 5:55-65.

Lewis G (1996) DSM-IV. Diagnostic and statistical manual of mental disorders. Psychol Med 26:651-652.

Maisonneuve IM, Glick SD (2003) Anti-addictive actions of an iboga alkaloid congener: a novel mechanism for a novel treatment. Pharmacol Biochem Behav 75:607-618.

Malin DH, Lake JR, Carter VA, Cunningham JS, Hebert KM, Conrad DL, Wilson OB (1994) The nicotinic antagonist mecamylamine precipitates nicotine abstinence syndrome in the rat. Psychopharmacology 115:180-184.

Marks MJ, Burch JB, Collins AC (1983) Effects of chronic nicotine infusion on tolerance development and nicotinic receptors. J Pharmacol Exp Ther 226:817-825.

Marubio LM, Arroyo-Jimenez MD, Cordero-Erausquin M, Lena C, Le Novere N, d'Exaerde AD, Huchet M, Damaj MI, Changeux JP (1999) Reduced antinociception in mice lacking neuronal nicotinic receptor subunits. Nature 398:805-810.

Nguyen HN, Rasmussen BA, Perry DC (2003) Subtype-selective upregulation by chronic nicotine of high-affinity nicotinic receptors in rat brain demonstrated by receptor autoradiography. J Pharmacol Exp Ther 307:1090-1097.

Papke RL, Sanberg PR, Shytle RD (2001) Analysis of mecamylamine stereoisomers on human nicotinic receptor subtypes. J Pharmacol Exp Ther 297:646-656.

Picciotto MR, Zoli M, Lena C, Bessis A, Lallemand Y, LeNovere N, Vincent P, Pich EM, Brulet P, Changeux JP (1995) Abnormal avoidance learning in mice lacking functional high-affinity nicotine receptor in the brain. Nature 374:65-67.

Picciotto MR, Zoli M, Rimondini R, Lena C, Marubio LM, Pich EM, Fuxe K, Changeux JP (1998) Acetylcholine receptors containing the beta2 sub- 
unit are involved in the reinforcing properties of nicotine. Nature 391:173-177.

Quick MW, Ceballos RM, Kasten M, McIntosh JM, Lester RA (1999) Alpha3beta4 subunit-containing nicotinic receptors dominate function in rat medial habenula neurons. Neuropharmacology 38:769-783.

Ross SA, Wong JY, Clifford JJ, Kinsella A, Massalas JS, Horne MK, Scheffer IE, Kola I, Waddington JL, Berkovic SF, Drago J (2000) Phenotypic characterization of an alpha 4 neuronal nicotinic acetylcholine receptor subunit knock-out mouse. J Neurosci 20:6431-6441.

Salas R, Pieri F, Fung B, Dani JA, De Biasi M (2003a) Altered anxiety-related responses in mutant mice lacking the $\beta 4$ subunit of the nicotinic receptor. J Neurosci 23:6255-6263.

Salas R, Orr-Urtreger A, Broide RS, Beaudet A, Paylor R, De Biasi M (2003b) The nicotinic acetylcholine receptor subunit alpha 5 mediates short-term effects of nicotine in vivo. Mol Pharmacol 63:1059-1066.

Salas R, Cook KD, Bassetto L, De Biasi M (2004) The $\alpha 3$ and $\beta 4$ acetylcholine receptor subunits are necessary for nicotine-induced seizures and hypolocomotion in mice. Neuropharmacology 47:401-407.

Schwartz RD, Kellar KJ (1983) Nicotinic cholinergic receptor binding sites in the brain: regulation in vivo. Science 220:214-216.
Sutherland RJ (1982) The dorsal diencephalic conduction system: a review of the anatomy and functions of the habenular complex. Neurosci Biobehav Rev 6:1-13.

Wang N, Orr-Urtreger A, Chapman J, Rabinowitz R, Korczyn AD (2003) Deficiency of nicotinic acetylcholine receptor beta 4 subunit causes autonomic cardiac and intestinal dysfunction. Mol Pharmacol 63:574-580.

Watkins SS, Stinus L, Koob GF, Markou A (2000) Reward and somatic changes during precipitated nicotine withdrawal in rats: centrally and peripherally mediated effects. J Pharmacol Exp Ther 292:1053-1064.

West RJ, Hajek P, Belcher M (1989) Severity of withdrawal symptoms as a predictor of outcome of an attempt to quit smoking. Psychol Med 19:981-985.

Wooltorton JR, Pidoplichko VI, Broide RS, Dani JA (2003) Differential desensitization and distribution of nicotinic acetylcholine receptor subtypes in midbrain dopamine areas. J Neurosci 23:3176-3185.

Xu W, Orr-Urtreger A, Nigro F, Gelber S, Sutcliffe CB, Armstrong D, Patrick JW, Role LW, Beaudet AL, De Biasi M (1999) Multiorgan autonomic dysfunction in mice lacking the $\beta 2$ and the $\beta 4$ subunits of neuronal nicotinic acetylcholine receptors. J Neurosci 19:9298-9305. 